\title{
DISCLOSURE DE PASSIVOS CONTINGENTES EM INSTITUIÇÕES BANCÁRIAS LISTADAS NA B3
}

\author{
Nome: Lorena de Mattos Barroso \\ Instituição: Universidade Federal dos Vales do Jequitinhonha e Mucuri - UFVJM \\ E-mail: lorenademattosbarroso@gmail.com
}

Nome: Lis Daiana Bessa Taveira

Instituição: Universidade Federal dos Vales do Jequitinhonha e Mucuri - UFVJM

E-mail: lisbessa@ hotmail.com

\author{
Nome: Roberto Silva da Penha \\ Instituição: Universidade Federal do Rio Grande do Norte - UFRN \\ E-mail: robertorrcontabilidade@hotmail.com
}

\section{RESUMO}

Este estudo busca verificar quais as características de divulgação dos Passivos Contingentes das Instituições bancárias listadas na B3 entre os anos de 2014 e 2017. Para consecução do objetivo, a metodologia utilizada foi pesquisa descritiva e documental, e abordagem de natureza qualitativa, com análise de relatórios anuais de instituições bancárias no Brasil, avaliando as demonstrações contábeis, com foco nas provisões o nos Passivos Contingentes. Os dados foram coletados nas demonstrações consolidadas no site da B3. Os resultados da pesquisa indicam haver divulgação principalmente de processos já em tramites judiciais, relacionados, a causas cíveis, trabalhistas e fiscais. Houve um alto índice de divulgação de passivos contingentes entre as empresas da amostra, o que denota a uma preocupação com o nível de disclosure das demonstrações financeiras analisadas.

Palavras-Chave: Passivo contingente. Instituições bancárias. Disclosure.

\begin{abstract}
This study seeks to verify the disclosure characteristics of Contingent Liabilities of Banking Institutions listed in B3 between 2014 and 2017. To achieve the objective, the methodology used was descriptive and documentary research, and qualitative approach, with analysis of reports. banking institutions in Brazil, evaluating the financial statements, focusing on provisions and contingent liabilities. Data were collected in the consolidated statements on the B3 website. The research results indicate that there is mainly disclosure of lawsuits already in court, related to civil, labor and tax cases. There was a high rate of disclosure of contingent liabilities among the sample companies, which indicates a concern with the level of disclosure of the financial statements analyzed.
\end{abstract}

Keywords: Contingent Liabilities. Banking Institutions. Disclosure.

\section{INTRODUÇÃO}

Ao longo dos anos, as mudanças no cenário contábil têm contribuído para atender de modo mais eficiente as necessidades de seus usuários. Diante deste contexto, as demonstrações contábeis podem ser grandes aliadas das organizações subsidiando as tomadas de decisões. Uma informação contábil se torna relevante quando altera a decisão do usuário 


\section{Revista \\ UNEMAT de \\ Contabilidade}

v. 10, n. 19,2021

(FRANCIS; OLSSON; SCHIPPER, 2006). Assim, os usuários serão providos de informações contábeis mais completas para analisar o comportamento da organização, através dos índices contábeis.

De acordo com Salotti e Yamamoto (2005), a Teoria da Divulgação tem como principal objetivo de estudo explicar o fenômeno da divulgação de informações financeiras a partir de várias perspectivas.

De acordo com Hendriksen e Breda (2007) a simples divulgação das informações não é o suficiente ao tempo e que tem que ser apresentadas de forma adequada, justa e completa possibilitando a transparência necessária.

A confiabilidade na mensuração do valor é fundamental para o registro das operações nas demonstrações contábeis. Segundo Conrado e Lopes (2011), o reconhecimento de elementos nas demonstrações contábeis deve ocorrer se for provável algum benefício econômico futuro associado a esse elemento e se ele possuir valor de custo ou puder ser mensurado de forma confiável. E completa que, além da preocupação com o registro das operações, as companhias devem cuidar da divulgação das políticas contábeis adotadas e a natureza das decisões tomadas.

Dessa forma, as demonstrações contábeis são elaboradas para atender os usuários finais com variados objetivos, nos casos das instituições bancárias um dos interessados nestes números são os investidores, pois se baseiam nos resultados financeiros para fazerem novos investimentos.

As instituições bancárias estão inseridas em um mercado caracterizado pelo ambiente de concorrência que induz a uma crescente busca pela melhoria da imagem e melhor eficiência nos procedimentos como um todo, principalmente pelo fato da dependência por recursos de terceiros para o avanço de suas atividades comerciais.

Sendo assim, os bancos atuam como intermediadores no mercado financeiro, captando recursos de terceiros através de aplicações que são oferecidas para o público externo, essas aplicações devem passar certo grau de confiabilidade para o investidor, que buscam informações sobre a instituição justamente em suas demonstrações contábeis. Um item que pode contribuir para aumentar o grau de transparência de uma instituição é o nível de disclosure das demonstrações contábeis, dentre os itens os Passivos Contingentes é um destes. Conforme definição do Pronunciamento 25 (CPC, 2009), são valores de possíveis obrigações ainda sem mensuração exata, e podem representar valores significativos no resultado das 


\section{Revista \\ UNEMAT de \\ Contabilidade}

v. 10, n. 19,2021

organizações, podendo influenciar a tomada de decisão. Os Passivos Contingentes mais comuns são os trabalhistas, os cíveis, os ambientais e fiscais (CPC, 2009).

Nesta mesma linha de pesquisa, o estudo de Ribeiro, Ribeiro e Weffort (2013), apresenta que a divulgação de contingências em notas explicativas aumentará a transparência no mercado, pois caso ocorram mudanças nos julgamentos e a empresa venha a incorrer em perdas ou ganhos futuramente, seus usuários já estarão cientes de tal fato. Como resultado da pesquisa, observou-se que no Brasil se provisiona consideravelmente o Passivo Contingente tributário, devido à legislação ser subjetiva e complexa, o que também facilita o gerenciamento de resultados.

Diante do exposto tem-se o seguinte objetivo de pesquisa verificar quais as características de divulgação dos Passivos Contingentes das Instituições bancárias listadas na B3 entre os anos de 2014 e 2017. Como problema de pesquisa verificar quais as características de divulgação dos Passivos Contingentes das Instituições bancárias listadas na B3 entre os anos de 2014 e 2017 ?

Para Gitman (2009), a respeito das informações contábeis das organizações, a maioria das entidades não vê o relatório anual unicamente como uma exigência, mas também como um importante veículo para influenciar as percepções dos investidores acerca da empresa e suas perspectivas futuras.

A qualidade das demonstrações contábeis está diretamente ligada a uma informação fidedigna e compatível com a realidade da instituição, resultando, consequentemente, numa melhor tomada de decisão. A divulgação das contingências ajuda na aproximação entre as contabilidades gerencial e financeira, exercendo uma importante influência na decisão de investimentos pelo fato de que nas contingências e nas provisões estão explicitados alguns riscos e situações adversas a qual a entidade pode estar exposta.

De acordo com os critérios adotados na mensuração e no reconhecimento das receitas, dos ganhos, das despesas e das perdas, o resultado líquido obtido pode, muitas vezes, apresentar-se diferente ou inverossímil, afetando a tomada de decisão dos investidores, a tributação e a sociedade. Diante disto, percebe-se a importância para a sociedade do correto reconhecimento e mensuração de todas as contas e fatos contábeis, visando a divulgação de resultados fidedignos.

\section{FUNDAMENTAÇÃO TEÓRICA}




\section{Revista \\ UNEMAT de \\ Contabilidade}

O Passivo vem ganhando importância devido às novas estratégias empresariais de captação de recursos e por questões jurídicas das obrigações financeiras. Os estudiosos Hendriksen e Breda (2007) comentam o conceito de passivos a luz da definição do Financial Accounting Standard Board (FASB) (1975) que os define como os sacrifícios futuros prováveis de benefícios econômicos resultantes de obrigações presentes de uma entidade, no sentido de transferir ativos ou serviços para outras entidades no futuro em conseqüência de transações e eventos passados.

Partindo para uma visão internacional, o International Accounting Standards Board (IASB) afirma que os passivos são provareis sacrifícios futuros dos benefícios econômicos que se levantas das obrigações atuais de uma entidade particular com o intuito de transferir os ativos ou fornecer serviços de outras entidades no futuro como consequências das transações e eventos passados (IASB, 2002).

De forma geral, o IASB (2002) elenca três principais características do passivo que são: I) a entidade assume a obrigação presente por meio de uma provável transferência futura de um ativo que foi requerido quando aconteceu um evento específico; II) a obrigação não pode ser evitada; III) o evento que obriga a entidade tem que ter ocorrido.

Santos et al. (2007) discorre o passivo pode resultar nas transações que permitem as organizações a obter recursos. De acordo com a Resolução 847 do Conselho Federal de Contabilidade (CFC, 1999), os passivos compreendem as origens dos recursos representados pelas obrigações para com terceiros. O Pronunciamento Conceitual Básico - CPC 00 (CPC, 2011, p. 23) define o passivo como "uma obrigação presente da entidade, derivada de eventos passados, cuja liquidação se espera que resulte na saída de recursos da entidade capazes de gerar benefícios econômicos".

Segundo Niyama e Silva (2011), reconhecer um passivo é incorporar no balanço patrimonial um determinado item que se enquadra na definição de passivo e que seja mensurável em bases confiáveis. Para Iudícibus (1999), boa parte das exigibilidades está associada ao reconhecimento de despesas e, portanto, o reconhecimento de uma despesa é o elemento mais importante para o reconhecimento de um passivo.

As exigibilidades podem ser encerradas, de acordo com Hendriksen e Breda (2007), pelos seguintes eventos: extinção da dívida: quando ocorre o pagamento; reestruturação de dívidas: quando são perdoadas inteira ou parcialmente pelo credor; desoneração em substância: quando ocorre que o devedor coloca dinheiro ou outros ativos, de maneira irrevogável, num fundo a ser utilizado exclusivamente para cumprir as obrigações de 


\section{Revista \\ UNEMAT de \\ Contabilidade}

v. 10, n. 19,2021

pagamento de juros e amortização de determinada dívida; desoneração instantânea: quando a empresa emite títulos de dívida e reserva de dinheiro imediatamente para permitir o resgate dessa dívida na época apropriada.

De forma geral, os Passivos Contingentes são considerados como obrigações possíveis, mas, o que os diferencia das provisões é que eles resultarão de eventos passados no quais a existência será confirmada a partir da ocorrência ou não de um evento futuro e incerto e que não está sob controle da entidade (CPC, 2009).

Para compreender melhor o tratamento contábil relacionado à possibilidade da ocorrência das provisões e contingências passivas, conforme apresentado no Quadro 1.

Quadro 1 - Contingências passivas e provisões

\begin{tabular}{|l|l|l|}
\hline \multicolumn{1}{|c|}{ Possibilidades } & \multicolumn{1}{|c|}{ Definição } & \multicolumn{1}{c|}{ Efeitos nas demonstrações } \\
\hline $\begin{array}{l}\text { Há obrigação presente com probabilidade } \\
\text { provável de saídas de recursos. }\end{array}$ & Provisão & $\begin{array}{l}\text { Reconhecido no } \\
\text { Patrimonial e divulgação. }\end{array}$ \\
\hline $\begin{array}{l}\text { Há obrigação possível ou obrigação } \\
\text { presente que pode requerer, mas } \\
\text { provavelmente não irá requerer uma saída } \\
\text { de recursos. }\end{array}$ & Passivo Contingente & Divulgado em nota explicativa. \\
\hline $\begin{array}{l}\text { Há obrigação possível ou obrigação } \\
\text { presente cuja probabilidade de uma saída } \\
\text { de recursos é remota. }\end{array}$ & $\begin{array}{l}\text { Não é Provisão e nem } \\
\text { Passivo Contingente }\end{array}$ & $\begin{array}{l}\text { Nenhum registro e/ou divulgação é } \\
\text { exigido. }\end{array}$ \\
\hline
\end{tabular}

Fonte: Adaptado do CPC (2009)

Os Passivos Contingentes podem ser considerados como uma obrigação presente que resulta de eventos do passado, só que não é reconhecida, uma vez que, não será provável uma saída de recursos para liquidar a obrigação.

De acordo com Gelbcke et al (2018), existem passivos que devem ser contabilizados, apesar de não terem data certa de liquidação ou não conter valor exato. Sendo assim, tem-se que a provisão é um passivo, porém é necessário diferenciar no balanço as provisões dos demais passivos, sendo a principal característica na classificação de provisão ou passivo a incerteza.

Assim, tendo como base as probabilidades de ocorrência das saídas dos recursos o CPC (2009) denomina o fato contábil como uma provisão ou um Passivo Contingente. Nesse contexto, orienta as empresas para que a cada provisão ou Passivo Contingente sejam reconhecidos os itens conforme Quadro 2, onde, de acordo com a característica, o valor é categorizado na classe de Provisão ou de Passivo Circulante (PC): 


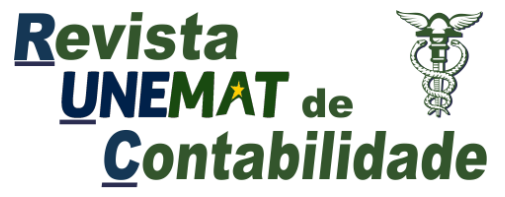

v. 10, n. 19,2021

Quadro 2 - Itens recomendados pelo CPC 25

\begin{tabular}{|l|c|}
\hline \multicolumn{1}{|c|}{ Itens de divulgação } & Classe \\
\hline O valor contábil no início do período & Provisão \\
\hline O valor contábil no fim do período & Provisão \\
\hline Provisões adicionais feitas no período, incluindo aumentos nas provisões existentes & Provisão \\
\hline Valores utilizados (ou seja, incorridos e baixados contra a provisão) durante o período & Provisão \\
\hline Valores não utilizados revertidos durante o período & Provisão \\
\hline $\begin{array}{l}\text { O aumento durante o período no valor descontado a valor presente proveniente da passagem do } \\
\text { tempo }\end{array}$ & Provisão \\
\hline O efeito de qualquer mudança na taxa de desconto & Provisão \\
\hline Uma breve descrição da natureza da obrigação & Provisão \\
\hline O cronograma esperado de quaisquer saídas de benefícios econômicos resultantes & Provisão \\
\hline Uma indicação das incertezas sobre o valor ou o cronograma dessas saídas. & Provisão \\
\hline $\begin{array}{l}\text { Sempre que necessário para fornecer informações adequadas, a entidade deve divulgar as principais } \\
\text { premissas adotadas em relação a eventos futuros, conforme tratado no item 48 do CPC 25 }\end{array}$ & Provisão \\
\hline $\begin{array}{l}\text { O valor de qualquer reembolso esperado, declarando o valor de qualquer ativo que tenha sido } \\
\text { reconhecido por conta desse reembolso esperado }\end{array}$ & Provisão \\
\hline $\begin{array}{l}\text { A entidade deve divulgar, para cada classe de Passivo Contingente na data do balanço, uma breve } \\
\text { descrição da natureza do Passivo Contingente }\end{array}$ & PC \\
\hline A estimativa do seu efeito financeiro, mensurada conforme os itens 36 a 52 do CPC 25 & PC \\
\hline A indicação das incertezas relacionadas ao valor ou momento de ocorrência de qualquer saída & PC \\
\hline A possibilidade de qualquer reembolso & PC \\
\hline $\begin{array}{l}\text { Quando a provisão e o Passivo Contingente surgirem do mesmo conjunto de circunstâncias, a } \\
\text { entidade deve fazer as divulgações requeridas pelos itens 84 a 86 do CPC 25 de maneira que } \\
\text { evidencie a ligação entre a provisão e o Passivo Contingente }\end{array}$ & Prov/PC \\
\hline $\begin{array}{l}\text { Quando algumas das informações exigidas pelos itens 86 e 89 do CPC 25 não forem divulgadas por } \\
\text { não ser praticável fazê-lo, a entidade deve divulgar esse fato. }\end{array}$ & Prov/PC \\
\hline
\end{tabular}

Fonte: Adaptado de CPC 25 (2009).

Os Passivos Contingentes, segundo o Statement of Financial Accounting Standards (SFAS) $n^{\circ} 5$ (1975) representam uma condição ou situação existente, um conjunto de circunstâncias e probabilidades envolvendo incerteza quanto a ganhos ou perdas possíveis para uma empresa, que será finalmente dirimida quando um ou mais eventos futuros ocorrerem ou deixarem de ocorrer, sendo que a resolução da incerteza poderá confirmar a existência ou não de um passivo.

O International Accounting Standards (IAS) nº 10 (1998), recomenda que deva ser provisionado o passivo sempre que houver a probabilidade estimável de perdas contingentes. As notas explicativas das demonstrações contábeis deverão ser utilizadas para registrar as contingências e os eventos ocorridos após a data de encerramento do balanço, bem como perdas esperadas, cujos valores possam ser superiores ao provisionado.

O Pronunciamento Técnico (CPC, 2009) conceitua provisão como um passivo de prazo ou de valor incertos cuja saída de recursos futuros é considerada provável. Um Passivo Contingente, por sua vez, seria uma saída de recursos possível, mas não provável (GELBCKE 


\section{Revista \\ UNEMAT de \\ Contabilidade}

v. 10, n. 19,2021

et al, 2018). Sendo assim, o que basicamente distingue um Passivo Contingente de uma provisão é a probabilidade da saída de recursos.

Conforme a Deliberação n 594, para que se reconheça uma provisão, é necessária, além da existência de uma obrigação presente, uma provável saída de recursos que incorporam benefícios econômicos para liquidar essa obrigação (CVM, 2009). Caso a probabilidade de ocorrência de tal desembolso seja menor do que provável, a entidade apenas fará a divulgação de um Passivo Contingente, através de notas explicativas. E, ainda, se a probabilidade de ocorrência for remota, não há lugar nem ao reconhecimento nem à divulgação de qualquer fato.

A inclusão dos Passivos Contingentes nas Demonstrações Contábeis é determinada por organismos internacionais FASB (1975) e IASB (2002) e pela legislação e normas contábeis brasileiras. Hendriksen e Breda (2007) consideram que, caso seja possível avaliar determinada obrigação, mesmo sendo sua realização provável, a exigibilidade deveria ser estimada e registrada. Todavia, se a obrigação tiver alta probabilidade de não se concretizar, a simples menção em nota explicativa é suficiente, originando o Passivo Contingente. Destacase o fato de o Passivo Contingente não poder ser reconhecido, entretanto deve ser divulgado (NIYAMA; SILVA, 2011), a não ser que seja remota a possibilidade de saída de recursos que incorporem benefícios econômicos para sua liquidação.

A Deliberação $n^{\circ} 594$ orienta que as responsabilidades contingentes devem ser divulgadas, completando com a descrição da natureza da obrigação e o cronograma esperado de quaisquer saídas de benefícios econômicos resultantes do Passivo Contingente; o valor contábil no início e no fim do período; provisões adicionais feitas no período; valores utilizados durante o período e valores não utilizados revertidos durante o período e outras exigências (CVM, 2009).

O CPC 25 (2009) é correlato às normas internacionais de contabilidade (IAS 37) e determina que um Passivo Contingente é: (a) uma obrigação possível que resulta de eventos passados e cuja existência será confirmada apenas pela ocorrência ou não de um ou mais eventos futuros incertos $\mathrm{E}$ não totalmente sob controle da entidade; ou (b) uma obrigação presente que resulta de eventos passados, mas que não é reconhecida porque: (i) não é provável que uma saída de recursos que incorporam benefícios econômicos seja exigida para liquidar a obrigação, ou (ii) o valor da obrigação não pode ser mensurado com suficiente confiabilidade. 


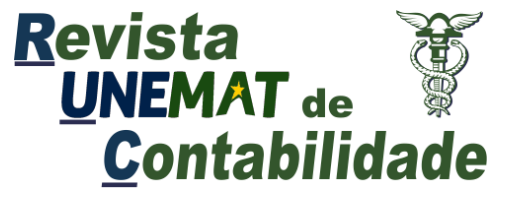

v. 10, n. 19,2021

Portanto, em uma visão geral, segundo Gelbcke et al (2018) a probabilidade de saída de recursos, as obrigações presentes tratadas devem ser avaliadas e classificadas em: a) provável, classificada como provisão; (b) possível, classificada como um Passivo Contingente divulgado; e (c) remota, classificada como um Passivo Contingente não divulgado.

A respeito do passivo trabalhista, as possíveis perdas decorrentes da não provisão de um possível passivo trabalhista podem comprometer as finanças da organização gerando um contingenciamento de despesas, afetando negativamente a saúde da empresa.

O Tribunal Superior do Trabalho (TST) mantém estatística das 100 pessoas jurídicas com maior número de obrigações trabalhistas perante a Justiça do Trabalho. De acordo com os dados atualizados até o dia 29 de junho de 2016, três das cem pessoas jurídicas listadas pelo TST são bancos, sendo que o Banco do Brasil S/A está em 14 lugar, com 1.178 demandas trabalhistas à época da pesquisa, em 31 ${ }^{\circ}$, a Caixa Econômica Federal, com 1.023, depois vem o Banco Bradesco S.A., em 96. Importante ressaltar que os dados são divulgados apenas por quantidade de processos, não sendo evidenciados os valores, em termos monetários, devidos pelas entidades.

Conforme Sperandio, Trindade e Fávero (2005), as contingências ambientais passivas podem apresentar três características: a) o cumprimento de exigências legais, para atender às imposições da legislação ou fazer face às penalidades por inobservância das referidas exigências legais em algum momento passado (recuperação ambiental, multa por infração a legislação pertinente à conservação do meio ambiente etc); b) a indenização, a terceiros, por prejuízos causados, e c) a prevenção em relação a eventos inesperados.

Costa et al (2017) afirmam que, devido à liberdade dada ao julgamento dos profissionais no reconhecimento dos Passivos Contingentes, a determinação destes pode sofrer a influência de características culturais como conservadorismo, uniformidade, flexibilidade, individualismo, entre outras. Em seu estudo sobre o disclosure dos Passivos Contingentes, onde foi feita uma análise comparativa entre as empresas de mercado aberto no Brasil e na Austrália, entre os anos 2010 e 2015, obtiveram como resultado que no Brasil, a categoria do Passivo Contingente predominante é a tributária, que corresponde a $56 \%$ do total de Passivos Contingentes evidenciados pelas companhias brasileiras, já na Austrália são as garantias, que correspondem quase à totalidade das contingências verificadas, ou seja, $98 \%$ do total.

\section{PROCEDIMENTOS METODOLÓGICOS}




\section{Revista \\ UNEMAT de \\ Contabilidade}

\subsection{Tipo da pesquisa}

Quanto aos objetivos do trabalho, a presente pesquisa é classificada como descritiva, uma vez que, busca descrever as características de determinada população ou fenômeno (GIL, 2008), com análise de relatórios anuais de instituições bancárias no Brasil, avaliando as demonstrações contábeis, com foco nas provisões o nos Passivos Contingentes.

A abordagem utilizada no trabalho pode ser caracterizada como de natureza qualitativa. No que concerne aos procedimentos adotados, o presente trabalho se caracteriza como uma pesquisa documental, pois consiste na utilização de materiais que ainda não receberam um tratamento analítico (GIL, 2008).

O procedimento adotado como técnica para o desenvolvimento da pesquisa é a análise de conteúdo, utilizada com o objetivo de trabalhar os dados brutos obtidos, na categoria de grade mista. Para Flick (2009), a análise de conteúdo, além de realizar a interpretação após a coleta dos dados, desenvolve-se por meio de técnicas mais ou menos refinadas.

\subsection{Universo e amostra}

Em relação ao universo e amostra, as análises foram feitas através do levantamento de dados das demonstrações financeiras e relatórios de administração das instituições bancárias brasileiras de capital aberto listadas na B3, a amostra foi analisada por conveniência não probabilística, com análise entre os anos de 2014 a 2017. As instituições bancárias de capital aberto inscritas na B3, objeto deste estudo são listadas no Quadro 3. 
Quadro 3 - Instituições bancárias listadas na B3

\begin{tabular}{|c|c|}
\hline BANCOS & CÓDIGO \\
\hline ALFA HOLDINGS S.A & RPAD \\
\hline BANCO INTER & BIDI \\
\hline BANESTES S.A - BCO EST ESPÍRITO SANTO & BEES \\
\hline BANCO ABC BRASIL S.A. & BBCB \\
\hline BANCO ALFA DE INVESTIMENTOS S.A & BAZA \\
\hline BANCO AMAZONIA S.A. & BBDC \\
\hline BANCO BRADESCO S.A. & BBAS \\
\hline BANCO DO BRASIL S.A. & BTGP \\
\hline BANCO BTG PACTUAL S.A. & BGIP \\
\hline BANCO DO ESTADO DE SERGIPE S.A. - BANESE & BPAR \\
\hline BANCO DO ESTADO DO PARA S.A & BRSR \\
\hline BANCO DO ESTADO DO RIO GRANDE DO SUL S.A. & IDVL \\
\hline BANCO INDUSVAL S.A. & BMIN \\
\hline BANCO MERCANTIL DE INVESTIMENTO S.A & BMEB \\
\hline BANCO MERCANTIL DO BRASIL S.AS & BNBR \\
\hline BANCO NORDESTE DO BRASIL S.A. & BPAN \\
\hline BANCO PAN S.A. & BPAT \\
\hline BANCO PATAGONIA S.A. & PINE \\
\hline BANCO PINE S.A. & SANB \\
\hline BANCO SANTANDER (BRASIL) S.A. & BSAN \\
\hline BANCO SANTANDER S.A. & BSLI \\
\hline BRB BANCO DE BRASILIA S.A. & BRGE \\
\hline ITAU UNIBANCO HOLDING S.A. & ITUB \\
\hline ITAUSA INVESTIMENTOS ITAU S.A. & ITSA \\
\hline PARANA BANCO S.A. & PRBC \\
\hline & \\
\hline & \\
\hline
\end{tabular}

Fonte: B3 (2017)

A respeito da comparabilidade, o CPC 00 (2011) destaca que a informação acerca da entidade será mais útil caso possa ser comparada com informação similar sobre outras entidades e com informação similar sobre a mesma entidade para outro período ou para outra data.

\subsection{Coleta e tratamento dos dados}

O roteiro para realização da pesquisa se iniciou com o acesso ao site da B3 e coleta das demonstrações contábeis, juntamente com as respectivas notas explicativas das instituições bancárias. Em um segundo momento, foram selecionadas as empresas que cumpriram alguns elementos e requisitos de evidenciação conforme os normativos do CPC 25 (2009) que trata dos Passivos Contingentes, ou seja, os bancos que fizeram a divulgação do Passivo Contingente em suas notas explicativas, nos quais foram listados em um quadro e atribuído a correspondência 1 para o banco que faz divulgação do Passivo Contingente e 0 para o banco que não faz essa divulgação. 


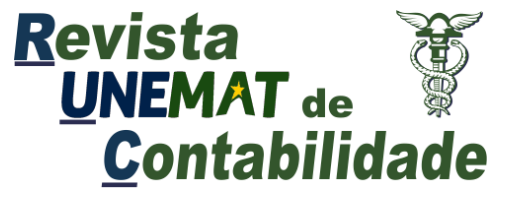

v. 10, n. 19,2021

Após a seleção das organizações e coleta das informações, a pesquisa seguiu com a verificação e análises da evidenciação dos Passivos Contingentes nas notas explicativas das demonstrações contábeis das empresas selecionadas. Em um estudo mais aprofundado, foi realizada uma análise da média dos Passivos Contingentes entre os maiores bancos da amostra. A apuração para seleção dos maiores bancos foi através do ranking anual do Valor Econômico dos 100 maiores bancos existentes no Brasil (VALOR ECONÔMICO, 2017).

\section{ANÁLISE DOS RESULTADOS}

\subsection{Divulgação dos passivos contingentes}

As contingências fiscais observadas nas divulgações das empresas estão relacionadas aos tributos em geral, inclusive previdenciários. As contingências trabalhistas geralmente envolvem reclamações judiciais por parte de funcionários e ex-funcionários das empresas, as contingências cíveis tratam de processos inerentes às atividades fins das empresas, geralmente são processos movidos por clientes buscando por indenizações, já o passivo ambiental é uma possível obrigação referente à proteção, recuperação e preservação do meio ambiente. Neste trabalho, especificamente, por serem empresas do setor bancário, não houve passivo contingente ambiental, devido à natureza das atividades dos bancos.

Considerando que o Passivo Contingente não deve ser registrado nos Balanços Patrimoniais, mas devem ser informados nas notas explicativas das demonstrações financeiras, dentre as Instituições Bancárias listadas na B3, foram analisadas as que divulgaram seus Passivos Contingentes, e em seguida, observado quais os tipos de contingências que aparecem em suas demonstrações financeiras e se são evidenciadas as informações mínimas recomendas pelos órgãos normativos aos quais elas estão submetidas.

A pesquisa utilizou-se do conceito dado pelos pronunciamentos técnicos do CPC 25 (2009), no que tange a divulgação dos Passivos Contingentes em notas explicativas pelas empresas. Na Tabela 1 consta a situação de divulgação ou não divulgação das empresas.

Tabela 1 - Divulgação dos Passivos Contingentes

BANCO INTER; BANESTES S.A - BCO EST ESPÍRITO SANTO; BANCO ABC BRASIL S.A.; BANCO ALFA DE INVESTIMENTOS S.A; BANCO AMAZONIA S.A.; BANCO BRADESCO S.A.; BANCO DO BRASIL S.A.; BANCO BTG PACTUAL S.A.; BANCO DO ESTADO DE SERGIPE S.A. - BANESE; BANCO DO ESTADO DO PARA S.A; BANCO DO ESTADO DO RIO GRANDE DO SUL S.A.; BANCO INDUSVAL S.A.; BANCO MERCANTIL DE INVESTIMENTO S.A; BANCO MERCANTIL DO BRASIL S.A; BANCO NORDESTE DO BRASIL S.A.; BANCO PAN S.A.; BANCO PINE S.A.; BANCO 


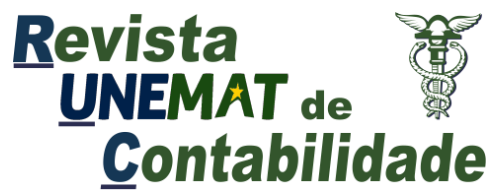

v. 10, n. 19,2021

SANTANDER (BRASIL) S.A.; BRB BANCO DE BRASILIA S.A.; ITAU UNIBANCO HOLDING S.A.; ITAU SA INVESTIMENTOS ITAU S.A.; PARANA BANCO S.A.

ALFA HOLDINGS S.A; BANCO PATAGONIA S.A.; BANCO SANTANDER S.A. Não divulgou

Fonte: Dados da pesquisa

Na Tabela 1 estão listadas as 25 Instituições Bancárias que fazem parte do objeto desta pesquisa, dentre elas, apenas 3 não divulgaram nenhuma espécie de Passivo Contingente, e 22 empresas que fizeram a divulgação, que representa $88 \%$ da amostra, onde, numa análise mais aprofundada dos dados, serão categorizados em tipos dos Passivos Contingentes.

Os 3 tipos de Passivos Contingentes mais frequentes encontrados foram os trabalhistas, os cíveis e os tributários, no entanto nem todas os bancos divulgaram valores de passivos nessas três modalidades. Nas próximas seções são apresentados os Passivos Contingentes por categoria.

\subsection{Passivo contingente trabalhista}

De acordo com as notas explicativas analisadas, as contingências trabalhistas, em geral, originam-se de ações judiciais movidas por terceiros que buscam obter indenizações referentes a pretensos direitos trabalhistas. Existem, também, outras reclamações de natureza trabalhista, tais como isonomia salarial, reintegração de demitidos, indenização por LER (Lesão por Esforço Repetitivo) e outros.

Na Tabela 2 apresentam-se os valores dos Passivos Contingentes na área Trabalhista divulgados pelas instituições bancárias, decorrentes do curso normal de suas atividades, onde se leva em conta a similaridade com processos anteriores, a complexidade e o posicionamento dos tribunais, e divulga o valor sempre que a perda for avaliada como provável. Há certo grau de subjetividade na definição dos valores a serem colocados nas Demonstrações Contábeis nesta área Trabalhista, necessitando sempre do conhecimento de um especialista no assunto, para tentar mensurar os valores da contingência o mais real possível.

Tabela 2 - Passivos Contingentes Trabalhistas (valores em milhares de reais)

\begin{tabular}{lrrrr}
\hline Instituições Bancárias listadas na B3 & $\mathbf{2 0 1 4}$ & $\mathbf{2 0 1 5}$ & $\mathbf{2 0 1 6}$ & $\mathbf{2 0 1 7}$ \\
\hline BANESTES S.A - BCO EST ESPÍRITO SANTO & 22.007 & 20.478 & 17.724 & 48.389 \\
BANCO ABC BRASIL S.A. & 6.107 & 9.635 & 13.178 & 22.997 \\
BANCO ALFA DE INVESTIMENTOS S.A. & 25.385 & 36.443 & 39.208 & 32.315 \\
BANCO AMAZONIA S.A. & 0 & 0 & 3.900 & 22.492 \\
BANCO DO BRASIL S.A. & 167.371 & 215.042 & 171.422 & 193.780 \\
\hline
\end{tabular}




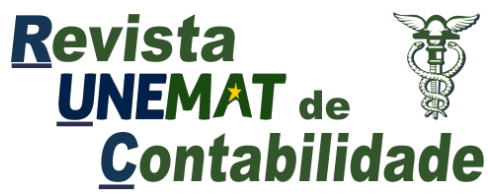

\begin{tabular}{lrrrr}
\hline BANCO DO ESTADO DE SERGIPE S.A. - BANESE & 18.102 & 19.010 & 26.754 & 34.475 \\
BANCO DO ESTADO DO PARA S.A. & 3.891 & 50.001 & 57.468 & 7.022 \\
BANCO DO ESTADO DO RIO GRANDE DO SUL S.A. & 752.687 & 948.420 & 1.164 .273 & 1.491 .689 \\
BANCO INDUSVAL S.A. & 6.881 & 4.878 & 16.114 & 4.702 \\
BANCO NORDESTE DO BRASIL S.A. & 420.988 & 449.031 & 88.073 & 463.666 \\
BRB BANCO DE BRASILIA S.A. & 12.953 & 19.422 & 18.262 & 19.182 \\
ITAU UNIBANCO HOLDING S.A. & 416.161 & 828.672 & 78.507 & 122.120 \\
ITAUSA INVESTIMENTOS ITAU S.A. & 15.000 & 25.000 & 40.000 & 88.000 \\
\hline Média & $\mathbf{1 4 3 . 6 5 6}$ & $\mathbf{2 0 2 . 0 0 2}$ & $\mathbf{1 3 3 . 4 5 3}$ & $\mathbf{1 9 6 . 2 1 8}$ \\
\hline
\end{tabular}

Fonte: Dados da pesquisa

Na Tabela 2 estão apresentados os valores dos Passivos Contingentes divulgados pelas Instituições Bancárias, em uma amostra de 25 bancos 13 tiveram valores divulgados da esfera trabalhista pouco mais de $50 \%$ da amostra total. O destaque para os Passivos Contingentes trabalhistas está no Banco do Estado do Rio Grande do Sul, que obteve o maior valor divulgado e o Banco Amazônia S.A., com os menores valores de divulgação. Nas demonstrações contábeis do Banco do Estado do Rio Grande do Sul consta que suas contingências trabalhistas, no que tange a natureza destes processos referem-se, principalmente, a pedidos de horas extras, reintegração e equiparação salarial.

Uma observação para o Banco Amazônia S.A. que até o ano de 2015 não fazia a divulgação do seu Passivo Contingente trabalhista e a partir de 2016 começou a fazer. Isso é algo muito frequente nas demonstrações contábeis, onde as empresas tendem a se adequar para se equiparar às demais instituições concorrentes.

\subsection{Passivo contingente cível}

Em análises às notas explicativas, percebeu-se que os processos cíveis se baseiam em sua maioria em pedidos relacionados aos Planos Econômicos (Plano Collor, Bresser e Verão), revisões contratuais e em indenizações por danos morais e materiais, nos quais a instituição atua como réu da ação. Existem algumas ações, em minoria, referente à devolução de cheques, inserção de informações sobre devedores no cadastro de restrições ao crédito e à restituição de valores em geral. 
Na Tabela 3 apresentam-se os valores dos Passivos Contingentes da área cível das Instituições Bancárias entre os anos 2014 e 2017, foram incluídos somente os bancos que tiverem algum registro neste tipo de Passivo Contingente.

Tabela 3 - Passivos Contingentes Cíveis (valores em milhares de reais)

\begin{tabular}{lrrrr}
\hline Instituições Bancárias listadas na B3 & $\mathbf{2 0 1 4}$ & $\mathbf{2 0 1 5}$ & $\mathbf{2 0 1 6}$ & $\mathbf{2 0 1 7}$ \\
\hline BANCO INTER & 26.132 & 14.220 & 20.487 & 50.308 \\
BANESTES S.A - BCO EST ESPÍRITO SANTO & 44.707 & 79.386 & 70.521 & 281.920 \\
BANCO ABC BRASIL S.A. & 29.189 & 7.593 & 5.198 & 2.804 \\
BANCO ALFA DE INVESTIMENTOS S.A. & 15.026 & 16.492 & 16.801 & 16.283 \\
BANCO AMAZONIA S.A. & 0 & 0 & 98.528 & 178.825 \\
BANCO DO BRASIL S.A. & 3.685 .014 & 3.270 .906 & 1.975 .843 & 2.327 .630 \\
BANCO DO ESTADO DE SERGIPE S.A. - BANESE & 5.944 & 10.543 & 11.555 & 11.042 \\
BCO. DO ESTADO DO RIO GRANDE DO SUL S.A. & 1.383 .948 & 1.673 .305 & 1.853 .365 & 1.832 .615 \\
BANCO INDUSVAL S.A. & 18.343 & 15.747 & 24.899 & 63.703 \\
BANCO MERCANTIL DO BRASIL S.AS & 843 & 911 & 986 & 1.047 \\
BANCO NORDESTE DO BRASIL S.A. & 77.777 & 47.955 & 72.857 & 69.904 \\
BANCO PINE S.A. & 0 & 95 & 578 & 0 \\
BANCO SANTANDER (BRASIL) S.A. & 658.000 & 728.000 & 1.211 .000 & 1.356 .000 \\
BRB BANCO DE BRASILIA S.A. & 350.486 & 193.297 & 282.496 & 234.927 \\
ITAU UNIBANCO HOLDING S.A. & 1.800 .483 & 2.459 .520 & 3.388 .219 & 3.493 .532 \\
ITAUSA INVESTIMENTOS ITAU S.A. & 7.000 & 8.000 & 7.000 & 10.000 \\
PARANA BANCO S.A. & 0 & 0 & 0 & 440 \\
\hline Média & $\mathbf{4 7 6 . 6 4 1}$ & $\mathbf{5 0 1 . 5 2 8}$ & $\mathbf{5 3 1 . 7 8 4}$ & $\mathbf{5 8 4 . 1 7 5}$ \\
\hline Fon DadOS
\end{tabular}

Fonte: Dados da pesquisa

Considerando-se o universo amostral, 17 instituições bancárias fizeram divulgação de Passivos Contingentes Cíveis, representando $68 \%$ da amostra, e 8 instituições não divulgaram, 32\% da amostra. Em relação ao Passivo Contingente Cível, as instituições analisadas que obtiveram os maiores valores divulgados foram o Banco do Brasil S.A e o Itaú Unibanco Holdings S.A.

\subsection{Passivo contingente tributário}

Várias instituições bancárias pesquisadas explicaram, em seus relatórios contábeis, que os valores constantes como Passivos Contingentes Fiscais vem, em sua maioria de valores referentes a processos relacionados aos impostos Confins (Contribuição para o Financiamento da Seguridade Social) e CSLL (Contribuição Social sobre o Lucro Líquido), por conta de questões tributárias ainda não resolvidas. 
Algumas instituições bancárias não divulgaram seus Passivos Contingentes Tributários, no entanto explicitaram em suas notas explicativas a respeito desta não divulgação, como é o caso do Banco Mercantil de Investimentos S.A. quando diz que "as principais ações do Banco Mercantil de Investimentos S.A, classificadas pela administração como possíveis, com base na avaliação de seus consultores jurídicos externos, são de natureza tributária e não totalizaram valores relevantes".

A Tabela 4 mostra os valores dos Passivos Contingentes divulgados pelas instituições bancárias.

Tabela 4 - Passivos Contingentes Fiscais (valores em milhares de reais)

\begin{tabular}{lrrrr}
\hline Instituições Bancárias listadas na B3 & $\mathbf{2 0 1 4}$ & $\mathbf{2 0 1 5}$ & $\mathbf{2 0 1 6}$ & $\mathbf{2 0 1 7}$ \\
\hline BANCO INTER & 0 & 0 & 107.772 & 126.211 \\
BANESTES S.A - BCO EST ESPÍRITO SANTO & 18.335 & 16.724 & 71.037 & 79.991 \\
BANCO ABC BRASIL S.A. & 103.061 & 295.594 & 276.669 & 380.328 \\
BANCO ALFA DE INVESTIMENTOS S.A. & 221.289 & 226.340 & 115.022 & 120.019 \\
BANCO BRADESCO S.A. & 8.744 .098 & 9.635 .037 & 16.483 .452 & 18.851 .729 \\
BANCO DO BRASIL S.A. & 10.840 .767 & 12.777 .102 & 10.702 .278 & 12.475 .951 \\
BANCO BTG PACTUAL S.A. & 3.092 .000 & 2.487 .000 & 2.811 .000 & 3.150 .000 \\
BANCO DO EST. DO RIO GRANDE DO SUL S.A. & 96.600 & 107.092 & 100.087 & 109.587 \\
BANCO INDUSVAL S.A. & 97.151 & 104.421 & 113.020 & 117.664 \\
BANCO MERCANTIL DE INVESTIMENTO S.A. & 0 & 0 & 1.930 & 1.980 \\
BANCO MERCANTIL DO BRASIL S.AS & 4.580 & 5.043 & 5.714 & 6.078 \\
BANCO NORDESTE DO BRASIL S.A. & 211.574 & 114.858 & 126.816 & 129.832 \\
BANCO PAN S.A. & 233.295 & 233.297 & 251.342 & 357.242 \\
BANCO PINE S.A. & 793 & 1.213 & 1.276 & 1.493 \\
BANCO SANTANDER (BRASIL) S.A. & 12.384 .000 & 14.469 .000 & 18.653 .000 & 18.741 .000 \\
BRB BANCO DE BRASILIA S.A. & 16.606 & 15.102 & 134.973 & 127.874 \\
ITAU UNIBANCO HOLDING S.A. & 14.172 .190 & 16.165 .417 & 18.106 .085 & 19.595 .293 \\
ITAUSA INVESTIMENTOS ITAU S.A. & 733.000 & 801.000 & 864.000 & 1.116 .000 \\
PARANA BANCO S.A. & 0 & 0 & 16.563 & 16.566 \\
\hline Média & $\mathbf{2 . 6 8 2 . 5 9 7}$ & $\mathbf{3 . 0 2 3 . 9 0 7}$ & $\mathbf{3 . 6 2 8 . 5 2 8}$ & $\mathbf{3 . 9 7 3 . 9 3 9}$ \\
\hline
\end{tabular}

Fonte: Dados da pesquisa

O total de notas explicativas que fizeram referência aos valores de Passivos Contingentes Fiscais foi de 19, correspondendo a 76\% da amostra. Somente 6 bancos não fizeram divulgação deste item, o que corresponde a $24 \%$ de abstenção. Dentre os tipos de Passivos Contingentes encontrados nesta pesquisa, o que obteve os maiores valores de média 


\section{Revista \\ UNEMAT de \\ Contabilidade}

v. 10, n. 19,2021

e a maior frequência de divulgação foi o fiscal, que compreende questões tributárias e previdenciárias.

Em relação ao aumento de divulgação durante os anos pesquisados, observa-se que 3 instituições que não divulgavam em 2014 e 2015 passaram a divulgar em 2016 e 2017, aumentando o seu grau de disclosure contábil, mostrando um crescimento de $12 \%$ na divulgação ao longo desses anos.

Das instituições analisadas, o Itaú Unibanco Holdings S.A, o Banco do Brasil S.A. e o Banco Santander (Brasil) S.A. apresentaram maiores valores na divulgação dos Passivos Contingentes fiscais. Uma observação para o Banestes S.A, que obteve uma variação significativa dos anos 2014 e 2015 para os anos de 2016 e 2017.

Uma observação para o Banco ABC Brasil, no valor do seu Passivo Contingente fiscal onde consta uma reserva, que segundo as Notas Explicativas de suas Demonstrações Financeiras Padronizadas, o Banco está defendendo autuação para pagamentos de encargos previdenciários, principalmente sobre valores pagos a título de participação nos lucros e resultados dos exercícios de 2006 a 2012.

\subsection{Análise de divulgação dos maiores bancos}

Com o objetivo de proporcionar possíveis explicações referentes aos valores divulgados nos Passivos Contingentes em comparação ao tamanho (ativo total) da empresa, realizou-se um estudo comparativo com o ranking divulgado pelo Valor Econômico.

Em análise às notas explicativas dos 20 maiores bancos listados no ranking do Valor Econômico, por ordem de Ativo Total, 8 deles figuram em nossa amostragem das instituições bancárias listadas na B3, que são, em ordem de maior para o menor: Itaú Unibanco Holding S.A., Banco Do Brasil S.A., Banco Bradesco S.A, Banco Santander (Brasil) S.A., Banco Btg Pactual S.A., Banco Pan S.A., Banco Abc Brasil S.A., Banestes S.A. Percebeu-se que o tamanho das empresas influencia positivamente com o nível de disclosure, pois estas 8 instituições bancárias fazem divulgação de seus Passivos Contingentes, 100\% da amostra pesquisada. Ou seja, selecionando os 8 maiores bancos constantes na amostra, verificou-se que todos eles fazem divulgação dos Passivos Contingentes.

Na Figura 1 observa-se a média de valores dos Passivos Contingentes divulgados dos 8 maiores bancos da amostra desta pesquisa nos anos de 2014 a 2017. 

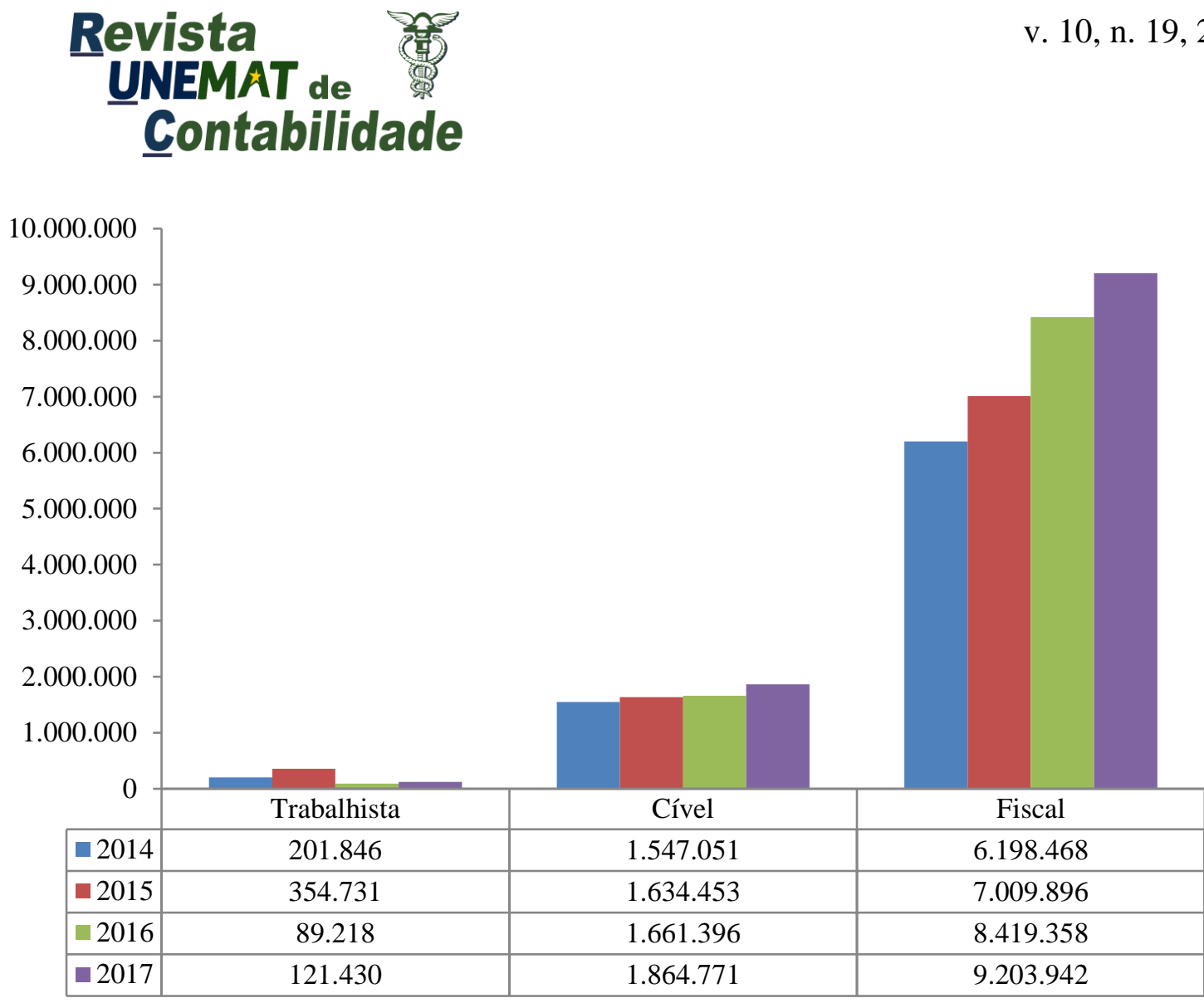

Figura 1 - Média dos Passivos Contingentes dos maiores bancos (valores em milhares de reais) Fonte: Dados da pesquisa.

No que se refere ao ano 2017, em uma análise mais aprofundada dos valores divulgados pelos maiores bancos dentro da amostra, obteve-se nos Passivos Contingentes trabalhistas uma média de divulgação em 2017 de R\$ 121.430,00. Em relação aos Passivos Contingentes cíveis, a média de divulgação entre os maiores bancos, no ano de 2017, foi de $\mathrm{R} \$ 1$ 1.864.771,00. E o mais expressivo e que obteve maior frequência dentro da amostra da pesquisa, a média dos Passivos Contingentes fiscais divulgados entre os maiores bancos em 2017 foi de R\$ 9.203.942,00. Observa-se o destaque para os Passivos Contingentes fiscais que possuem valores muito superiores aos demais tipos, mostrando a prevalência destas nas empresas investigadas.

\section{CONSIDERAÇÕES FINAIS}

A mensuração em valores de um Passivo Contingente é uma tarefa bem complexa dentro da contabilidade, que dependem de acontecimentos futuros e até mesmo que independem da organização, como por exemplo, uma decisão judicial.

A proposta da pesquisa foi verificar quais as características de divulgação dos Passivos Contingentes das Instituições bancárias listadas na B3 entre os anos de 2014 e 2017. Tal 


\section{Revista \\ UNEMAT de \\ Contabilidade}

v. 10, n. 19,2021

análise foi feita de acordo com os critérios dados pelos pronunciamentos técnicos do CPC 25 (2009).

Um dos objetivos do CPC 25 (2009) é de que seja divulgada informação suficiente nas notas explicativas das organizações, para permitir que os usuários da informação contábil entendam sua natureza, grau de importância, probabilidade e valor. Assim, dada a importância da contabilidade gerencial e financeira, a omissão ou inclusão de passivos contingentes nas demonstrações contábeis pode afetar a tomada de decisões dos usuários das informações contábeis e, em alguns, caracterizar gerenciamento de resultados.

Em resposta aos objetivos deste trabalho, após análise das notas explicativas da amostra, que totalizaram 100 relatórios financeiros (25 empresas em 4 anos), constatou-se que, apesar de serem do mesmo setor, o de instituições bancárias, com os mesmos riscos do negócio e mesmas normas regulatórias a seguir, a frequência da divulgação dos passivos contingentes se diferenciou de um banco para outro.

Ao analisar as notas explicativas, obteve-se como resultado que $88 \%$ das empresas fazem divulgação do seu Passivo Contingente, o que representa 22 instituições da amostra composta por 25. Ao considerar os passivos contingentes por categorias percebeu-se que a categoria mais comum foi a Fiscal, seguindo pelo Cível e o terceiro mais frequente, os Passivos Contingentes Trabalhistas.

De acordo com os critérios adotados na mensuração e no reconhecimento das receitas, dos ganhos, das despesas e das perdas, o resultado líquido obtido pode, muitas vezes, apresentar-se diferente, afetando a tomada de decisão dos investidores, a tributação e a sociedade. Ainda, a inclusão de valores nas contas de Provisões de modo indevido poderia resultar na suavização dos resultados contábeis, podendo a instituição beneficiar-se indevidamente de alguma forma. Diante disto, percebe-se a importância do correto reconhecimento e mensuração de todas as contas e fatos contábeis, visando a divulgação de resultados fidedignos, o apoio nas tomadas de decisões e a prevenção ao gerenciamento de resultados.

A pesquisa tem como limitações a amostra analisada, composta somente das instituições bancárias e o período de análise. Sendo assim, os números, resultados e conclusões obtidos nesta pesquisa não poderão ser generalizados para todas as organizações, tendo em vista que o estudo se concentrou, apenas, nas instituições bancárias listadas na B3. Como sugestão para trabalhos futuros, poderia se aplicar a mesma metodologia deste trabalho 


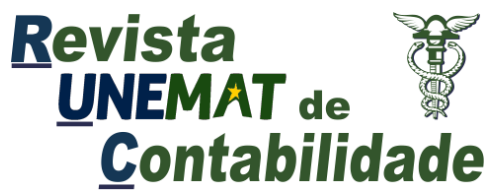

v. 10, n. 19,2021

em outros setores, pois os resultados obtidos nesta pesquisa podem conter vieses oriundos do setor bancário.

\section{REFERÊNCIAS}

BRASIL, BOLSA, BALCÃO - B3. Empresas listadas. Disponível em $<$ http://www.b3.com.br/pt_br/>. Acesso em: 10 jul. 2018.

COMISSÃO DE VALORES MOBILIÁRIOS - CVM. Deliberação 594 de 15 de setembro de 2009. Aprova o Pronunciamento Técnico CPC 25 do Comitê de Pronunciamentos Contábeis, que trata de provisões, passivos contingentes e ativos contingentes. Diário Oficial [da]

República Federativa do Brasil, Brasília, DF, 16 set. 2009. Disponível em < http://www.cvm.gov.br/legislacao/deliberacoes/deli0500/deli594.html>. Acesso em: 10 jul. 2018.

COMITÊ DE PRONUNCIAMENTOS CONTÁBEIS - CPC. Pronunciamento Técnico CPC 00 - Provisões, Passivos Contingentes e Ativos Contingentes. 2011. Disponível em $<$ http://www.cpc.org.br/CPC/Documentos-

Emitidos/Pronunciamentos/Pronunciamento?Id=80>. Acesso em: 18 jul. 2018.

Pronunciamento Técnico CPC 25 R1 - Provisões, Passivos Contingentes e Ativos

Contingentes. 2009. Disponível em <http://www.cpc.org.br/CPC/Documentos-

Emitidos/Pronunciamentos/Pronunciamento?Id=56>. Acesso em: 18 jul. 2018.

CONRADO, S.; LOPES, M. V. Transparência e qualidade das demonstrações contábeis.

Revista Capital Aberto. n 100, dez. 2011. Disponível em

$<$ https://capitalaberto.com.br/boletins/transparencia-e-qualidade-das-demonstracoescontabeis/\#.WhAy90qnHIU>. Acesso em: 11 nov. 2017.

CONSELHO FEDERAL DE CONTABILIDADE - CFC. Resolução nº. 847/99. Altera a redação da NBC T3 - Conceito, Conteúdo, Estrutura e Nomenclatura das Demonstrações Contábeis e dá outras providências. Diário Oficial [da] República Federativa do Brasil, Brasília, DF, 08 jul. 1999. Disponível em <http://www.portaldecontabilidade.com.br/nbc/res847.htm>. Acesso em: 12 nov. 2017.

COSTA, I. L. S; CORREIA, T. S.; MACHADO, M. R.; LUCENA, W. G. L. Disclosure dos passivos contingentes: Análise comparativa entre empresas de mercado aberto no Brasil e na Austrália. Pensar Contábil. v. 19, n. 69, p. 54-66, 2017.

FINANCIAL ACCOUNTING STANDARDS BOARD - FASB. STATEMENT OF FINANCIAL ACCOUNTING STANDARDS n5 - SFAS 5. Accounting for Contingencies. Issued: March 1975, IN: Original Pronouncements. John Wiley: New York, edition 2002/2003.

FLICK, U. Introdução à pesquisa qualitativa. 3. ed. São Paulo: Artmed, 2009.

FRANCIS, J.; OLSSON, P.; SCHIPPER, K. Earnings Quality. Foundations and Trends in Accounting, v. 1, n. 4, p. 259-340, 2006. 
GELBCKE, E. R.; SANTOS, A.; IUDÍCIBUS, S.; MARTINS, E. Manual de contabilidade societária aplicável a todas as sociedades: de acordo com as normas internacionais e do CPC. 3. ed. São Paulo: Atlas, 2018.

GIL, A. C. Como elaborar projetos de pesquisa. 4. ed. São Paulo: Atlas, 2008.

GITMAN, L. J. Princípios de Administração Financeira. 12. ed. São Paulo: Pearson, 2009.

HENDRIKSEN, E. S.; BREDA, M. F. V. Teoria da Contabilidade. 5. ed. São Paulo: Atlas, 2007.

IASB - International Accounting Standards Board. IAS 37 - Provisions, Contingent

Liabilities and Contingent Assets. Londres: IASB, 2002. Disponível em

$<$ https://www.ifrs.org/issued-standards/list-of-standards/ias-37-provisions-contingentliabilities-and-contingent-assets/>. Acesso em: 22 jul. 2018

IUDÍCIBUS, S. Teoria da Contabilidade. 5. ed. São Paulo: Atlas, 1999.

NIYAMA, J. K.; SILVA, C. A. T. Teoria da Contabilidade. São Paulo: Atlas, 2011.

RIBEIRO, A. C.; RIBEIRO, M.S.; WEFFORT, E. F. J. Provisões, contingências e o pronunciamento CPC 25: as percepções dos protagonistas envolvidos. Revista Universo Contábil, v. 9, n. 3, 2013.

SALOTTI, B. M.; YAMAMOTO, M. M. Ensaio sobre a Teoria da Divulgação. Brazilian Business Review, v. 2, n. 1, p. 53-70, 2005.

SANTOS, J. L.; SCHMIDT, P. FERNANDES L. A. MACHADO, N. P. Teoria da Contabilidade: introdutória, intermediária e avançada. São Paulo: Atlas, 2007.

SPERANDIO, L. A; TRINDADE, M.; FAVERO, H. L. Uma Introdução à Discussão do Passivo Ambiental. Revista Enfoque Reflexão Contábil, v. 24, n. 2, p. 5-18, 2005.

TRIBUNAL SUPERIOR DO TRABALHO. Estatísticas da CNDT. Disponível em: <http://www.tst.jus.br/estatistica-do-cndt>. Acesso em: 18 jun. 2017.

VALOR ECONÔMICO. Valor 1000. Jornal Valor Econômico. 2017. Disponível em: < https://www.valor.com.br/valor1000/2017/ranking100maioresbancos>. Acesso em: 20 jul. 2018. 